\title{
Da Grécia antiga à România medieval: o topos "mãe e filha" na literatura
}

Viviane Cunha

Universidade Federal de Minas Gerais

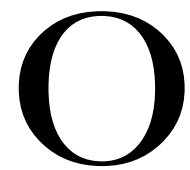

s hinos homéricos - coleção de prelúdios do gênero cantado pelos aedos numa espécie de introdução aos seus lais apresentam uma grande variedade de temas e de discursos, já que, foram compostos em diferentes épocas, e em diferentes regiões da antiga Grécia. Apesar da nomenclatura, apenas um desses hinos é atribuído a Homero. Não pretendemos, porém, fazer aqui, uma análise dos hinos homéricos; é o bino a Deméter que tem uma particular importância para este estudo.

Duas obras importantes, sobre os hinos homéricos, nos direcionam neste trabalho: uma antologia bilingüe, que apresenta a tradução inglesa de todos os hinos homéricos, elaborada por Evelyn-White (2000), e uma obra editada por Foley (1999), abrangendo vários ensaios, que analisam o poema de Deméter e Perséfone sob diferentes abordagens. Segundo Foley

The author or authors of the poem are unknown, but scholars argue for a date between 650-550 B.C.E. on stylistic and historical grounds. (...) the poet (or poets) who composed this text are working in a tradition where individual contributions are impossible to distinguish. (...) its dialectical idiosyncracies are most easily explained by an Attic origin. ${ }^{1}$

O bino a Deméter narra a angústia e o desespero de uma mulher, em razão do rapto de sua filha. A observação do mito de Deméter e Perséfone nesse poema permite-nos visualizar, não apenas o universo "mãe e filha", do ponto de vista do narrador, mas pode-se entrever ainda, em algumas passagens do hino, o discurso direto entre as duas mulheres, no momento em que elas se reencontram, depois do rapto de Perséfone.

${ }^{1}$ FOLEY, 1999, p. 29. 
Como nos ensina a mitologia, Deméter (ou Ceres, na mitologia romana) é a mãe de Coré (Korê "a Virgem") ou Perséfone (Prosérpina, na mitologia romana), que anda sem destino à procura de sua filha, a qual havia sido raptada por Hades. Somente Hécate e Hélios foram testemunhos dos gritos de Perséfone, no momento em que ela foi levada aos Infernos, pelo deus do Olimpo.

Desesperada, Deméter vaga sem descanso sobre a terra, durante nove dias e nove noites, carregando uma tocha acesa, sem se banhar, "sem se alimentar de ambrosia e de um copo de néctar", ${ }^{2}$ procurando por sua filha, ignorando, porém, o rapto dela, que fora tramado por Hades e Zeus. No décimo dia, Deméter encontra Hécate que a leva até Hélios, "aquele que vê todas as coisas", ${ }^{3} \mathrm{O}$ qual se enche de piedade pela mãe infeliz, e lhe revela o nome do raptor de Perséfone. Deméter, tomada de cólera ao tomar conhecimento da trama dos dois deuses, recusa-se a retornar ao Olimpo, e ali permanecer. Continuando a percorrer o seu caminho, ela acaba encontrando acolhida em Celeus, rei de Elêusis, e sua mulher Metâneira, que ignoram a identidade da deusa, e a tomam por uma simples ama de seu filho Demofoon (ou Triptôlemos, segundo alguns autores), a quem Deméter transmite a imortalidade.

Todavia, depois da partida de Deméter, do Olimpo, a terra tornase estéril e a fome ataca os mortais, o que preocupa Zeus. Esse intervém junto a Hades, para que devolva a filha a Deméter, o que ele recusa a fazer, porque havia forçado Perséfone, contra a sua vontade, a ingerir algumas sementes de romã, enquanto ela se encontrava no domínio dos mortos, o que a impedia de retornar ao mundo dos vivos.

Não, sem uma certa relutância, foi estabelecido, finalmente, um acordo entre os dois deuses e a deusa do Olimpo: Perséfone passaria duas partes do ano, no mundo dos vivos, com sua mãe, e as outras duas partes, no mundo dos mortos, com Hades, seu esposo. Encontra-se aqui a base do mito das estações: o tempo que Perséfone passa com sua mãe são as belas estações - primavera e verão - época das boas colheitas dos frutos da terra; o tempo que ela passa com Hades são o outono e o inverno, época em que as sementes ficam sob a terra, "um lugar escuro". Isto está na origem dos mistérios de Elêusis, que celebram o culto a Deméter, e consideram essa lenda, como um símbolo perpétuo de morte

\footnotetext{
${ }^{2}$ Minha trad. a partir do ingl. HENDERSON, 2000, p. 289-324.

${ }^{3}$ HENDERSON, 2000, p. 289-324.
} 
e de ressurreição. O culto eleusiniano dos frutos anuais da terra tornouse muito importante para os povos gregos.

Na Grécia antiga, o culto a Deméter foi celebrado, primeiramente, pelas mulheres. Por todo o mundo grego, os arqueólogos encontraram uma grande quantidade de terracotas, concernentes ao universo feminino, e santuários dedicados às deusas, nos quais, as mulheres desempenhavam um papel ativo, principalmente, no culto a Deméter. O Museu Nacional de Atenas possui estátuas de Deméter que datam do século XVI A.C., o que demonstra a antigüidade de seu culto. Nas regiões do sul da Itália, que constituem a Magna Graecia, encontram-se igualmente, vestígios de santuários dedicados a Perséfone: alguns museus do Sul da Itália possuem um acervo significativo de estátuas da deusa. Com efeito, segundo Graham (1997),

certos cultos, dos mais importantes, se deslocaram da Creta minóica ao continente da Grécia, no decorrer da idade do bronze; é o caso dos cultos de Deméter e de Perséfone, que, segundo a mitologia grega, foram levados a Elêusis por Teseu, primeiro rei de Atenas, após ele ter vencido o lendário Minotauro, no templo-palácio de Cnossos em Creta. (minha trad., a partir da trad. franc.) ${ }^{4}$

Os mistérios de Elêusis são os mais importantes cultos de mistérios da antigüidade, e, eventualmente, atraíam iniciados de todo o mundo greco-romano, como observa Foley (1999), num artigo em que comenta o hino a Deméter. No período clássico (480-323 A.C.) - não se tem certeza de quem participaria, quando o hino foi composto -, uma grande parte dos atenienses, inclusive mulheres e escravos, assim como os outros povos gregos eram iniciados nos mistérios. Eles prometiam um começo de felicidade, nesta vida, e uma pós-vida bastante diferente. ${ }^{5}$

Se a narrativa do mito de Deméter e Perséfone nos encanta pelo seu conteúdo, não o faz menos pelo discurso da mãe, assim como o da filha, no momento em que elas se reencontram. A relação entre as duas deusas engloba, de certa forma, um dos arquétipos do mito da criação. Como bem observou Jung, a humanidade é dotada de um "inconsciente coletivo" estruturado por "arquétipos", esquemas comuns a todos os homens,

${ }^{4}$ GRAHAM, 1999, p. 23.

${ }^{5}$ Cf. The Homeric Hymn to Demeter. (Translation). 
exprimindo-se por imagens simbólicas, entre outras, através do mito; daí o seu poder de fascinação (apud Willis, 1995).

Seabra (2000), num capítulo intitulado "Amor entre mãe e filha: Deméter e Perséfone", faz uma interessante abordagem do mito das duas deusas. Nas palavras da autora, "mito e cotidiano são os fios que tecem um quadro - o retrato de mãe e filha - que nos toca por ter certas qualidades que lhe são próprias". A primeira dessas qualidades "é uma intimidade absoluta, particular a essa relação que impressiona tanto por suas manifestações positivas como negativas". ${ }^{6}$

A partir de uma fundamentação biológica, Rich (1976) afirma que "provavelmente não há nada na natureza humana com cargas mais ressonantes que o fluxo de energia entre dois corpos biologicamente semelhantes, um dos quais flutuou no líquido amniótico dentro do outro, um dos quais trabalhou para dar à luz o outro".?

Outra qualidade - "tão essencial e única quanto a intimidade" - é uma dimensão de continuidade, que foi analisada por Jung:

Poderíamos, portanto, dizer que toda mãe contém a filha em si mesma e toda filha, a mãe; e que toda mulher projeta-se para trás estendendose na mãe e para a frente, na filha. Essa participação e "entremeação" produz uma estranha incerteza no que concerne ao tempo; a mulher vive antes como mãe e mais tarde como filha. A experiência consciente desses laços produz o sentimento de que sua vida está espalhada sobre gerações - o primeiro passo na direção da experiência imediata e convicção de estar fora do tempo, que traz consigo um sentimento de imortalidade.?

A intimidade e a continuidade "revelam que mãe e filha são dois pólos do mesmo ser: mulher" (Seabra, 2000). Criativamente ou destrutivamente, a filha busca na mãe a sua identidade e a mãe busca realização na existência da filha. "Uma existência dá sentido à outra".

A intimidade, em seus múltiplos aspectos, "tanto na fruição e no gozo, como no sofrimento que ela gera”, está descrita na primeira parte

\footnotetext{
${ }^{6}$ SEABRA, 2000, p. 13.

${ }^{7}$ RICH apud SEABRA, 2000, p. 13.

${ }^{8}$ SEABRA, 2000, p. 13.

9 JUNG apud SEABRA, 2000, p. 13-14.
} 
do bino a Deméter. a convivência das duas deusas. O tema da continuidade é desenvolvido na parte final: o retorno e o não-retorno de Perséfone. A ruptura das duas vivências se insere na segunda e terceira partes: o rapto e a ausência de Perséfone. "São interpretações que procuram desvendar, absorver e integrar um mito que, no entanto, foi e continua sendo inesgotável" (Seabra, 2000). O mito das duas deusas é "(...) uma sementeira de experiência feminina para mulheres de todos os tempos e lugares, nas palavras de Luke (1981)". ${ }^{10}$

As relações entre mãe e filha são, sem dúvida, um tema universal, e a literatura medieval utilizou largamente esse topos, tanto nas canções de mulheres, como nos romances corteses. A Belle das chansons de toile francesas, que se apresenta como um personagem a fazer trabalhos manuais (a fiandeira, a tecedeira, a bordadeira, a costureira), aparece, às vezes, em companhia da mãe. Veja-se, por exemplo, a canção Bele Yolanz en chambre koie (Bartsch 6, Zink VI), uma tenção, onde a mãe e a filha discutem, enquanto tecem. Yolanz (ou Yolande) não faz seu trabalho corretamente, já que encontra-se distraída, o que desagrada à mãe. A filha pergunta à mãe porque esta lhe reprova:

III

- Mere, de coi me chastoiez?

Est ceu de coudre ou de taillier, ou de filer, ou de broissier, ou se c?est de trop somillier?<smiles>[Mg]</smiles>

"Mãe, de que me reprovais?

É de costurar ou de cortar, é de fiar, ou é de bordar, ou é de estar muito sonolenta"

A mãe responde, na quarta estrofe, que a reprova por outro motivo, e não pelas razões arroladas na terceira estrofe, supra citada:

IV

Ne de coudre ne de taillier, ne de filer, ne de broissier,

\footnotetext{
${ }^{10}$ LUKE apud SEABRA, 2000, p. 14.

${ }^{11}$ Cit. a partir de ZINK, 1978, p. 96.
} 
ne ceu n'est de trop somillier; mais trop parlez au chevalier. ${ }^{11}$

(...)

"Não é de costurar, não é de cortar, não é de fiar, não é de bordar, nem é de sentir tanto sono; mas, porque conversais muito com o cavalheiro".

A mãe de Yolande a reprova, pelo fato de ela muito conversar com o conde Mahi, sendo ela uma mulher casada, como mostram os dois primeiros versos da $5^{\mathrm{a}}$ estrofe: "Trop parlez au conte Mabi, / si en poise vostre mari, (...)" "Muito falais ao conde Mabi, / assim envenena [de ciúme] o vosso marido (...)". Yolande mostra-se sonolenta, enquanto faz seus trabalhos manuais, e nessa reação, talvez se possa descodificar um certo tédio, face a um trabalho, que não deixa de ser repetitivo. Os trabalhos de tecer e de fiar, principais atividades femininas em tempos passados (ou mesmo, nos tempos atuais, em várias comunidades), não deixam de ser um determinismo social, já que estão sempre associados às mulheres.

Numa análise da iconografia, que representa a mulher na Idade Média, precisamente, do século X ao XII, Frugoni (1977) observa que, nessa época, quase não há representações da mulher relacionada com as profissões, e, de maneira geral, com todo o trabalho; "a única ocupação que lhe é atribuída é o de fiandeira: um trabalho mecânico, passivo, solitário, que a encerra nos limites de sua família e de sua casa". ${ }^{12}$ (trad. por mim a partir do francês)

É possível, que a figura da tecelã representada nas canções de mulheres da Idade Média, seja um emblema daquela que contesta uma situação social, que lhe fora imposta: permanecer em casa a fazer trabalhos caseiros, entre outros, de costuras e bordados, de tecer e de fiar, excluída da vida extra-muros. Como bem observa Regnier-Bohler, nas chansons de toile francesas, "a noção de fronteira é marcada, freqüentemente, por uma situação de dependência da actante feminina, e por uma revolta virtual perante a instituição de um casamento temido ou acabado" (trad. por mim a partir do francês).

As canções medievais do universo românico, que apresentam a mulher, enquanto sujeito do discurso, revelam uma espécie de denúncia

${ }^{12}$ FRUGONI, 1977, p. 178. 
social, o que levou Cremonesi (1984) a afirmar que os poetas medievais estão sempre do lado das mulheres. É bem possível, que exatamente no âmbito do universo feminino, eles tenham encontrado matéria substanciosa e diversificada, e ainda uma certa originalidade, como tema de sua poesia. A representação da mulher, no seu espaço privado, o que se passa entre ela e o seu meio ambiente, sugerido ou real, como mãe ou como governanta, é marcado por um certo fechamento, uma certa barreira, e uma sensação de imutabilidade. O tempo lírico-narrativo é o da espera de um outro tempo, onde a falta será, talvez preenchida. ${ }^{13}$

É possível, que a representação recorrente da mulher a fazer trabalhos manuais, na literatura da Idade Média, tenha alguma relação com os mitos gregos ou com os topoi literários, largamente absorvidos e remanejados pelo imaginário ocidental, em que Penélope seria, talvez, o exemplo mais emblemático, principalmente no que se refere ao trabalho de tecer, enquanto se espera. Alguns poemas de Safo e os poucos versos que nos chegaram de Érina, também mostram a figura da tecedeira, e no caso dessa última, aparece a figura da mãe, no poema intitulado "Não iremos mais ao bosque":[4]

As bonecas eram todas as nossas preocupações de meninas, a brincar de esposas, esquecidas, em nossos quartos;

antes do fim do dia, a mãe, que havia distribuído a lã, às servas fiandeiras, chegava, e pedia ajuda para salpicar a carne. ${ }^{14}$

As cantigas de amigo galego-portuguesas apresentam igualmente o topos mãe e filha, e essa repetição do tema - tanto no universo ibérico, quanto na poesia da Idade Média, em geral - pode significar mais do que uma simples relação entre personagens. Pode tratar-se, na verdade, da representação de um microcosmos, no qual a mulher devia desempenhar um papel importante, seja como genitora, seja como educadora, já que a literatura reflete, muitas vezes, uma realidade social.

Além dos sentidos observados acima, as chansons de toile apresentam uma relação com o mito de Deméter e Perséfone: nas canções francesas, as duas figuras - mãe e filha - em geral, estão muito ligadas, o que nos remete ao princípio da continuidade, do qual fala Jung (op. cit.).

${ }^{13}$ REGNIER-BOHLER, 1984, p. 393.

${ }_{14}^{14}$ Trad. port. por mim, a partir da trad. franc., publ. por BATTISTINI, 1997, p. 171. 
Os fios usados pelas duas personagens das canções francesas - mãe e filha - ao executarem a tarefa de tecer, fiar ou bordar, simbolizam bem esse elo que une as gerações.

Por outro lado, as cantigas de amigo galego-portuguesas apresentam, também, as duas figuras, mãe e filha, em relações conflituosas: de autoridade, de rivalidade, etc., como se pode verificar na canção de Pero Meogo (B 1192, V 797), a qual apresenta um exemplo de mãe autoritária:

- "Digades, filha, mia filha velida, porque tardastes na fontana fría? - "Os amores ei."

- Digades, filha mia filha louçana, porque tardastes na fría fontana?"

-"Os amores ei."

"Tardei, mia madre, na fontana fría, cervos do monte a augua volvían.

- "Os amores ei."

Tardei, mia madre, na fría fontana, cervos do monte volvían a augua."

- "Os amores ei."

- "Mentís, mia filha, mentís por amigo, nunca vi cervo que volvess' o río. - "Os amores ei"

- Mentís, mia filha, mentís por amado, nunca vi cervo que volvess'o alto".

"Os amores ei." 15

A mãe não acredita quando a filha lhe diz a causa de sua demora na fonte, ou seja, de que os cervos haviam turvado a água (III, 2 e IV, 2), porque sabe de antemão, que esse é um pretexto do encontro amoroso; ela argumenta, pois, repreendendo a filha. Assim, tanto a canção de tela francesa, quanto a cantiga de amigo galego-portuguesa, apresentam topoi comuns, isto é, o das mães guardiãs, que zelam pela boa reputação da filha.

${ }^{15}$ Cit. a partir de BREA (coord.), 1996, p. 872. 
O mundo medieval é um mundo, sobretudo guerreiro, como se sabe, e não é somente a literatura - através das canções de gesta - que nos fornece um rico repertório do topos da guerra. É, principalmente, a História, que nos apresenta um retrato, bastante próximo, dessa realidade. Em geral, a sociedade medieval é apresentada, na literatura, de forma dualista: de um lado as canções de gesta, expressando o mundo guerreiro, e de outro lado, as canções trovadorescas, enunciando o amor cortês, para falarmos apenas dos gêneros literários mais canônicos, e dos séculos que são aqui tratados: XII e XIII. Os temas relacionados à tópica amorosa deviam servir para moderar a violência: o amor cortês teria aí uma função, não apenas social, mas, também, essencial. As mães e as filhas das canções representariam um topos social, que permitiria um certo equilíbrio, num lugar onde a força masculina era sinônimo de prestígio. Se a mulher estava, sempre, em segundo plano, em quase todas as atividades da vida feudal, havia, pelo menos algumas, em que ela tinha um papel fundamental, como o de moderadora, educadora e administradora dos bens domésticos.

As cantigas de amigo galego-portuguesas apresentam numerosos exemplos de topoi da mãe ou madre, além do exemplo supra citado de Pero Meogo. Num estudo intitulado, "Madre y cantiga de amigo", Juarez Blanquer (1994) observou que, no corpus das cantigas de amigo do cancioneiro galego-português, a figura da mãe aparece em 130 poemas, e, praticamente, na metade deles, ela é tão importante quanto o amante, tornando-se mesmo, verdadeira protagonista, e a única voz, em 11 cantigas. Segundo a filóloga espanhola, a mãe é uma figura "multifacetada", isto é, as mães retratadas, nas cantigas, apresentam atos e comportamentos os mais variados, o que torna difícil uma classificação tipológica. Apesar disso, Juarez Blanquer tenta e consegue apresentar uma galeria de mães bastante cativantes, tais como: a "mãe vigilante", a "mãe confidente", a "mãe cúmplice da filha", etc. Todos esses tipos de mães podem ser agrupados, de uma maneira geral, segundo a sua taxonomia, em: a mãe guardiã da virgindade da filha, isto é, aquela que a reprime quando ela chega tarde em casa, proibindo-a de falar com o amigo, que é quase uma inimiga; e a outra, inteiramente amigável, que ouve os queixumes da filha, e, algumas vezes, a ajuda e lhe dá conselhos. Segundo Juarez Blanquer,

${ }^{16}$ BLANQUER, 1994, p. 138. 
No cabe duda que, en un género tan abundante en lugares comunes como éste, donde se repiten con tanta frecuencia, frases, versos y aun estribillos, la madre no deja de ser un pretexto literario, pero también es cierto que existe una realidad de fondo, una situación familiar, mas o menos sofisticada, pero auténtica en profundidad, como asimismo podemos afirmarlo facilmente del círculo femenino que rodea a la muchacha: donas, amigas, irmanas, tantas veces invocadas ... ${ }^{16}$

Já, Corral Diaz (1996), que estudou a figura da mulher, nas cantigas medievais, observou que, madre é um dos vocábulos mais freqüentes, na poesia trovadoresca. Nas cantigas galego-portuguesas - depois de molher, dona, senhor e amiga - madre aparece em 137 composições, incluindose aí as cantigas de escárnio, as cantigas de amor e as cantigas de amigo. Essa especialização do termo, e a sua situação no incipit de 63 canções faz pensar, nas palavras da autora, que trata-se de uma marca distintiva de gênero, da mesma maneira, que os termos senhor amiga distinguem as cantigas de amor e de amigo, respectivamente.

Enfim, resta ressaltar que no bino a Deméter, existe uma espécie de arremate do poema, onde é a voz do aedo que se faz ouvir. Essa prática será muito utilizada no lirismo da Idade Média, principalmente nas canções das trobairitz occitanas, em algumas chansons de toile, e, também, nas cantigas galego-portuguesas, nas quais são freqüentes as tornadas, os envois e as fiindas (sendo essas últimas mais típicas das cantigas de amor). Ouçamos, pois, a voz do aedo, no final do poema de Deméter e Perséfone (vv. 490-495), o qual cito a partir de Evelyn-White:

E agora, rainha da doce terra de Elêusis, e do mar Paros e da montanha Antron, senhora, que nos traz bons presentes, portadora das boas estações, rainha das deusas, sejais cheia de graça, vós e vossa filha, a lindíssima Perséfone, e por minha canção, conceda-me substância para alegrar-me o coração. ${ }^{14}$

${ }^{14}$ Minha trad. a partir da trad. inglesa. EVELYN-WHITE, 2000, p.325. 


\section{Referências Bibliográficas}

BARTSCH, K. Altfranzosische Romanzen und Pastourellen. Leipzig: s. e., 1870. BATTISTINI, Y. Poétesses grecques. Paris: Imprimerie Nationale, 1997.

BREA, M. (Coord.) et alii. Lírica Profana Galego-Portuguesa. Corpus Completo das cantigas medievais, con estudio biográfico, análise retórica e bibliografía específica. 1a. ed. Santiago de Compostela: Xunta de Galicia, 1996, 2 v., 1077 p.

CORRAL DIAZ, E. As mulheres nas cantigas medievais. Santiago de Compostela: Publications de Estudos Galegos, 1996.

CREMONESI, C. Chansons de geste e chansons de toile. Studi Romanzi di Filologia e Letteratura. Brescia: s.e., 1984, p. 3-120.

EVELYN-WHITE, H. G. (Transl.) Hesiod Homeric Hymns Epic Cicle Homerica. Ed. by J. HENDERSON. Loeb Classical Library. Cambridge (Mass.) \& London: Harvard University Press, 2000, p. 289-324.

FOLEY, H. P. (Ed.) et alii The Homeric Hymn to Demeter. Translation, Commentary and Interpretative Essays. Princeton: Princeton University Press, 1999.

FRUGONI, C. L?iconographie de la femme au cours des Xe-XIIe siècles. Cabiers de Civilisation Médiévale, XXe Année, n. 2-3 (1977) p. 177-188.

GRAHAM, L. Déesses. Tradução do original inglês Goddesses por J. DAVID. New York, Paris, Londres: Editions Abbeville, 1997.

JUAREZ BLANQUER, A. Collectanea de Estudios Filológicos (Lingüística, Léxico, Lírica y Retórica). Granada: Universidad de Granada, 1994.

REGNIER-BOHLER, D. Geste, Parole et Clôture: Les représentations du gynecée dans la littérature médiévale du XIIIe au XVe siècle. Mélanges de langue et de littérature médiévales offerts à Alice Planche. Annales de la Faculté des Lettres et Sciences Humaines de Nice, nE 48, 1984.

SEABRA, Z. Amor entre mãe e filha: Deméter e Perséfone. In: Quatro Amores. São Paulo: Record, 1997.

WILLIS, R. (Dir.) Mythologies du monde entier. Paris: France Loisirs, 1995.

ZINK, M. Les chansons de toile. Paris: Honoré Champion, 1978. 


\section{Resumo}

O topos "mãe e filha" aparece nas mais diferentes literaturas, de épocas diversas, o que demonstra a sua produtividade. Podemos encontrá-lo, por exemplo, nos hinos homéricos, mais precisamente, no Hino a Deméter. Este estudo tem por objetivo observar o tema "mãe e filha" na poesia grega e nas canções de mulheres da România medieval, focalizando os espaços galo-românico e ibero-românico.

\section{Résumé}

Le topos "mère et fille" apparaît dans bien des littératures, à diverses époques, ce qui confirme la productivité de ce sujet. On le trouve, par exemple, dans les hymnes homériques, en particulier dans l'Hymne à Déméter. Cette étude analyse le topos "mère et fille" dans la poésie grecque et dans les chansons de femmes de la Romania médiévale, principalement dans les espaces gallo-roman et ibéro-roman. 